This item was submitted to Loughborough's Research Repository by the author.

Items in Figshare are protected by copyright, with all rights reserved, unless otherwise indicated.

\title{
Testing the relationships between motivation and future intention in physical activity: Does governmental financial support matter?
}

PLEASE CITE THE PUBLISHED VERSION

https://doi.org/10.1080/02188791.2019.1603100

\section{PUBLISHER}

(C) National Institute of Education, Singapore. Published by Taylor \& Francis (Routledge)

\section{VERSION}

AM (Accepted Manuscript)

\section{PUBLISHER STATEMENT}

This is an Accepted Manuscript of an article published by Taylor \& Francis in Asia Pacific Journal of Education on 24 Apr 2019], available online: https://doi.org/10.1080/02188791.2019.1603100

\section{LICENCE}

CC BY-NC-ND 4.0

\section{REPOSITORY RECORD}

Kwon, Hyungil Harry, Do Young Pyun, and J.Y. Kim. 2019. "Testing the Relationships Between Motivation and Future Intention in Physical Activity: Does Governmental Financial Support Matter?”. figshare. https://hdl.handle.net/2134/37419. 
1 Running Head: MOTIVATION IN PHYSICAL ACTIVITY

2

3

4

5

6

7

8

9

10 Testing the Relationships between Motivation and Future Intention in Physical Activity: Does

Governmental Financial Support Matter?

12

13

14

15

16

17

18

19

20

21

22

23

24

25 
2 As a new sport policy, named 'School Sport Promotion Group (SSPG)', the Korea

3 government selected 50 schools in 2011 and 2012. Each school was granted with US\$40,000

4 a year for a three-year term. The purpose of this study was to examine the effectiveness of the

5 SSPG programme when it pertained to students' motivation and participation in school sport

6 clubs. More specifically, the moderation effect of governmental financial support in the

7 relationships between motivation (intrinsic and extrinsic) and sport participation was tested

8 using structural equation modeling. The results indicated that both intrinsic motivation $(\beta$

$9=.22)$ and extrinsic motivation $(\beta=.20)$ were significant indicators of future participation

10 intention in non-SSPG model while only intrinsic motivation $(\beta=.58)$ was a significant

11 indicator in SSPG model. A chi-square differential test showed that the coefficient of the path

12 from intrinsic motivation to future intention in the SSPG was significantly larger than that in

13 non-SSPG model, supporting the moderation role of governmental financial support. The

14 results of this study can provide administrators with meaningful information regarding how

15 financial support can promote students' physical activity and health.

17 Keywords: intrinsic motivation, extrinsic motivation, participation intention, physical 18 activity, governmental financial intervention 


\section{Introduction}

2 The obesity rate among Korean adolescents has been increasing mainly due to their sedentary

3 life style and increased fast-food consumption (Statistics Korea, 2018). According to the

4 results from the Programme for International Student Assessment 2015 (OECD, 2018), 14\%

5 of 15 years old Korean students do not participate in any physical activities outside school,

6 which is much higher than the average rate among OECD countries (i.e., 7\%). A recent

7 governmental report on Korean students' physical health indicated that $17.3 \%$ of

elementary/middle/high school students were obese in 2017, which increased from $11.2 \%$ in

9 2008 (Ministry of Education, 2018).

To improve adolescents' physical health, the government introduced the 'School Sport Club' scheme in 2007 to reinforce the extracurricular physical activities in schools. The government seeks to explore the degree to which the governmental financial support could further enhance the effectiveness of the extracurricular physical activity programme (i.e., school sport club) as evidenced in past literature (Brownson, Kelly, Eyler, Carnoske, Grost, Handy, \& Schmid, 2008; Siedentop, 2009; Story, Nanney, \& Schwartz, 2009). Brownson et al. (2008) highlighted that policy and environmental interventions could result in supporting sustained physical activities. Furthermore, Siedentop (2009) and Story et al. (2009) insisted that a substantial increase in funding at the federal and local governmental levels is necessary to improve the quantity and quality of physical activity and exercise in school programmes. For the improvement of health among Korean adolescents, the Korean government has selected 50 schools (i.e., 10 elementary, 20 middle, and 20 high schools) and provided each school with US $\$ 40,000$ a year for a three-year term so that the schools are able to provide students with better quality of sport activities without extra charges. Those schools with the government subsidy are labeled as 'School Sport Promotion Group (SSPG)'. The schools selected for this programme are able to use the budget to hire quality instructors to improve 
1 and expand their school sport clubs and to provide free or low priced programmes to students.

2 The government recommends the schools not to use the budget for the purposes of renovating

3 or building new sport facilities. This is because the budget itself is not big enough to make a

4 considerable change in their facilities. Another reason is that the government seeks to develop

5 a feasible model through which sport club programme can be sustained without a huge

6 investment on existing school sport facilities.

Although the financial support is supposed to increase the quantity and quality of sport programmes in the SSPG schools, its effectiveness has not yet been evaluated.

Particularly, little attention has been paid to examine the effectiveness in regards to whether students in the SSPG schools are more intrinsically motivated to participate in school sport club programmes. Thus, the main objective of the study was to examine if the financial support for extracurricular physical activity could effectively enhance students' intrinsic motivation towards sport club programmes and influence their future intention to keep participating in the programmes. The results of the study can provide valuable information regarding how the financial support can promote students' physical activity and health. Based on this information, the government will be able to make a better decision whether they need to continue supporting SSPG schools or not. In addition, the results of the study will also suggest an administrative blueprint with which the policy initiative can improve extracurricular physical activities in any countries whose situation is similar to the Republic of Korea.

\section{Theoretical Background and Research Hypotheses Development}

The effectiveness of the policy intervention was examined in this study. On the basis of the self-determination theory framework (e.g., Deci \& Ryan, 1985, 2002), this study included two antecedents of sport participation intention: students' intrinsic motivation and extrinsic motivation. More specifically, the study aimed to test if the governmental financial support could moderate the relationships between both intrinsic and extrinsic motivation and future 
1 behavioural intention.

2 Motivation and Sport Participation

3 Motivation is defined as the process that influences the initiation, direction, strength,

4 persistence, and quality of certain outcomes (Roberts \& Treasure, 2012). Since young

5 students are considered active and controlling agents in the learning process of sport, their

6 initial motivation of participating in sport activities determines diverse outcomes of such

7 activities (Bryan \& Solmon, 2012). A theoretical foundation of motivation in sport activities

8 can be conceptualised in the self-determination theory of Deci and Ryan (1985, 2002). The

9 self-determination theory suggests that motivation is conceptualised as a continuum where

10 diverse types of motivations are placed, from amotivation at one end to intrinsic motivation at

11 the other end (Deci \& Ryan, 1985). Between amotivation and intrinsic motivation, four

12 different extrinsic motivational regulations are placed: external regulation, introjected

13 regulation, identified regulation, and integrated regulation. Although the four extrinsic

14 motivations differ in terms of the level of external influence on participants, they are similar

15 in that participation is motivated by external factors to a certain extent.

16 The organismic integration theory (Deci \& Ryan, 1985, 2002), which is one of the

17 sub-theories of the self-determination approach explains "the process by which people

18 assimilate behaviours that are externally regulated and incorporate them into their repertoire

19 of behaviours that are self-determined and integrated into their personal system" (Hagger \&

20 Chatzisarantis, 2008, p. 81). That is, the concept addresses that various forms of extrinsic

21 motivation vary in their relative autonomy and sometimes become self-determined (Ryan,

22 Williams, Patrick, \& Deci, 2009). It may infer that for sport participation with a recreational

23 purpose such as school sport clubs, external rewards or contingences can be also significant

24 factors to positively lead to sport participation. A plethora of empirical evidence in motivation

25 literature supports that still many people do exercise with extrinsic motivation and goals such 
1 as gaining separable outcomes (e.g., tangible/social reward), rather than inherent enjoyment

2 or interest (e.g., Alexandris, Tsorbatzoudis, \& Grouios, 2002; Ryan et al., 2009; Tsorbatzoudis,

3 Alexandris, Zahariadis, \& Grouios, 2006). Alexandris, Tsorbatzoudis, and Grouios (2002)

4 found the positive impact of extrinsic motivation on the frequency of sport participation,

5 highlighting that "external reasons such as health and fitness, attractiveness, general

6 appearance, weight control, are important incentives towards sport and exercise participation"

7 (p. 248-9).

Different from extrinsic motivation, the concept of intrinsic motivation was

9 developed based on the cognitive evaluation theory (Deci \& Ryan, 1985), which proposed

10 that "experiences of competence and autonomy are necessary conditions for the maintenance

11 and enhancement of intrinsic motivation" (Ryan \& Deci, 2007, p. 3). Intrinsic motivation among students is thought to be more relevant than other types of motivations as their participation in school sport clubs is voluntary in nature. The participants choose their sport activities based on their preference. They form their own teams and also set up their own training schedules. Intrinsic motivation of self-determination theory emphasises the importance of autonomy. The nature of their participation is very self-regulated, indicating that their behaviour is sustained by the experience of enjoyment and self-interest (Deci \& Ryan, 2002). Previous literature has emphasised the importance of intrinsic motivation among students when it pertains to their participation in physical education and other types of sport activities (Ryan \& Deci, 2007). The role of intrinsic motivation has been well documented in other literature. The empirical findings indicated that intrinsically motivated behaviour among children were related to positive consequences such as psychological wellbeing, high-quality learning, persistence, effort, achievement, and future academic success (Burton et al., 2006; Deci \& Ryan, 1987; Lepper, Corpus, \& Iyengar, 2005; Linnenbrink \& 
1 activity level as well as academic achievement (Howe \& Freedson, 2008; Vazou, Gavrilou,

2 Mamalaki, Papanastasiou, \& Sioumala, 2012). Further, children who were intrinsically

3 motivated in sport tended to be more physically active after their school years (Spitath \&

4 Spitath, 2005). On the basis of the self-determination theory as a theoretical framework, the

5 following hypotheses were developed (see Figure 1):

Hypothesis 1: There will be a positive relationship between intrinsic motivation and future intention to participate in school sport clubs among young students.

Hypothesis 2: There will be a positive relationship between extrinsic motivation and future intention to participate in school sport clubs among young students.

\section{Moderation Effect of Governmental Finance Support}

Policy makers are increasingly interested in the implementations of various funding programme schemes to promote more active sport participations. In the UK, the concept of 'specialist sports college' was introduced for the purposes of talent development and elite development at school level (Houlihan, 2000). With a belief that schools should play a significant role on the pursuit of active sporting culture, the government has established this policy initiative (Houlihan, 2000). Siedentop (2009) proposed a legal framework that could continuously provide schools with financial support to improve quantity and quality of physical activities among pupils. Additionally, the government would develop "clear expectations for quantity and quality of [physical activities] programs in schools, surveillance systems to monitor district compliance in meeting those expectations, and an accountability system aimed at ensuring that [government] expectations are being met with assistance for districts that do not meet expectations" (Siedentop, 2009, p. 168). Such policy interventions are usually designed to promote pupils to be more physically active by enabling schools to offer a wide range of sport programmes accommodating more students and quality instructors teaching systematic skills and techniques necessary to sport participation. 
There are substantial evidences to support the effectiveness of policy interventions at the governmental level for the promotion of physical activities. For instance, the Finland government introduced a series of national physical activity policies between 1991 and 2002 with significant amount of funding to design supportive programmes and facilities and to strengthen the infrastructure and networks for the services (Pratt et al., 2015). As a result, Finnish people's physical activity times have significantly increased (Vuori, Lankenau, \& Pratt, 2004). Thus, a government-led policy development and financial investment could play a significant moderating role in improving participation in exercise and physical activity in school settings, by promoting motivation (e.g. value, norms, expectation, attitude) among pupils. More specifically, the government initiatives and the favourable school environments would therefore result in an increase in students' competence which leads to increased sport participations.

Competence refers to the need to produce behavioural outcomes and the ability to effectively carry out these planned behavioural outcomes (Deci \& Ryan, 2000). Along with autonomy and relatedness, competence is one of three innate psychological needs (Deci \& Ryan, 2000). A competence-support intervention that provides various sport club choices, effective coaching method, and quality equipment is directly related to intrinsic motivation which is an important determinant of participating in sport clubs. Martindale, Collins, and Daubney (2005) systematically reviewed past literature to identify critical environmental or contextual factors for effective sport development. Among the Martindale et al.'s (2005, p. 353) five identifications of environmental factors (e.g., "long-term aims and methods, wide ranging coherent message sand support, emphasis on appropriate development rather than early selection, and individualised and ongoing development, and integrated, holistic, and systematic development"), coherent message and support (e.g., hiring more coaches and sport staffs) and individualised and ongoing development (e.g., providing various sport 
1 programmes) are, in particular, closely related to the current SSPG scheme. These external

2 environmental factors are important nutrients that increase intrinsic motivation (Martindale et

3 al., 2005). Intrinsically motivated students would be more likely to participate in school sport

4 club activities due to the inherent enjoyment and self-interest that the school environment

5 provides. In addition, providing more physical activity opportunities in schools positively

6 influences youth developmental outcomes such as physical fitness (Story et al., 2009),

7 academic performance (Bradley, Keane, \& Crawford, 2013), and social interactions

8 (Allender, Cowburn, \& Foster, 2006), which are all attributes related to extrinsic motivation. Thus, it is predicted that the impacts of intrinsic and extrinsic motivation on future intention to participate in school sport clubs would vary depending on the extent to which the governmental financial support is provided. More specifically, the following two hypotheses were developed (see Figure 1).

Hypothesis 3: The relationship between intrinsic motivation and participation intention would be stronger among the students in SSPG schools than those in nonSSPG schools.

Hypothesis 4: The relationship between extrinsic motivation and participation intention would be stronger among the students in non-SSPG schools than those in SSPG schools.

\#\#\#Insert Figure 1 around here\#\#\#

\section{Participants}

\section{Method}

The participants of the study were 571 students (304 men and 259 women; eight students did not indicate) from SSPG and 573 students (413 men and 160 women) from nonSSPG. The SSPG schools received financial support in both 2011 and 2012 from the government. The government selected 29 middle and high schools for this financial 
1 intervention in 2011 and added 21 more schools (elementary, middle, and high schools) in

2 2012. However, the schools selected in 2012 were not included in this study because an one-

3 year window was not expected to be long enough for the schools to adopt quality programme

4 in their sport clubs.

5

6 with a similar size and similar characteristics (i.e., co-ed, status of schools, etc.),

The researchers listed up all 29 SSPG schools and selected one non-SSPG school corresponding to each SSPG school in the same region. A total of 58 (29 SSPG and 29 nonSSPG) schools were selected as a research population frame. An official letter from the government (i.e., Ministry of Education) was sent to the schools seeking full cooperation to data collection. After receiving the school principal's approvals, the questionnaires were mailed to each school. PE teachers of the schools were provided with the detailed instructions on the data collection. The PE teachers then distributed the questionnaires to the participants in their sport clubs. They were instructed to select the respondents from as many different clubs as possible. The PE teachers collected the completed questionnaires and mailed them back to the researchers. Each school returned around 30 questionnaires to the researchers.

\section{Instrument Development}

The data were collected using a questionnaire that includes the motivation scale and a single item measuring future intention to participate in school sport clubs. At the end of the questionnaire, demographic items were included to measure respondents' gender, school type (i.e., middle school or high school), and year of the study. Both intrinsic and extrinsic motivation measures were adapted from Guay, Vallerand, and Blanchard (2000). The participants were asked to answer three items of intrinsic motivation and three items of extrinsic motivation that described the reasons why they participated in school sport club. A 7-point Likert scale was used for all items. The five-phase study conducted by Guay et al. (2000) validated the psychometric properties of the motivation measures. The future intention 
1 was measured with a single item (i.e., 'Do you want to participate in a school sport club next

2 year?'), which was also anchored with a 7-point Likert scale. Although there has been

3 criticism on using a single item measure (see Marchevsky, 1999; Oshagbemi, 1999), the use

4 of a single item has increased in many disciplines such as business (Nagy, 2002), education

5 (Wanous \& Hudy, 2001), and psychology (Robins, Hendin, \& Trzesniewski, 2001). In

6 addition, Nunnally and Bernstein (1994) indicates that a single item will suffice when the

7 domain is simple and few observable variables are available. The future intention to

8 participate in school sport club is thought to be a simple conative variable that can be

9 measured with s single item.

10 Data Analyses

At a preliminary stage, firstly, data were examined for missing values and outliers.

After the data were screened, descriptive statistics were calculated. Next, for the hypotheses testing, two data groups (i.e., non-SSPG and SSPG) were prepared. For each group, structural equation modeling (SEM) was conducted. The current study employed SEM over other possible choices because a very efficient estimation technique for researchers to test both measurement and structural model simultaneously (Hair, Black, Babin, Anderson, \& Tatham, 2006). The measurement model examined the overall (goodness-of-fit) and internal (reliability and validity) model fit. The structural model included the proposed relationships between motivation and future participation intention was also tested. However, it should be noted that SEM could cause a common variance bias derived from its measurement method rather than natural correlations among the latent variables (Podsakoff, MacKenzie, Lee, \& Podsakoff, 2003). Lastly, a multigroup invariance test of SEM was employed to test a significant difference in strengths of the path parameter estimates across the two groups. In this invariance test, a fully constrained model whose all parameters were imposed to be equal across the two groups $(\mathrm{Ho})$ is compared with the unconstrained model which the path 
1 between intrinsic motivation and future intention was freely estimated $\left(\mathrm{H}_{\mathrm{A}}\right)$. As the two

2 models were in nested sequence, a chi-square difference test can be utilised for this comparative procedure. With one degree of freedom difference, it would be concluded that the change was statistically significant at the .05 probability level if a chi-square change is greater than 3.84. All analyses in the hypotheses testing were carried out using LISREL 8.80.

\section{Results}

\section{Model Fit in the Structural Models}

The descriptive statistics of all variables in the non-SSPG and SSPG data sets were calculated. No missing or invalid value was found. The normality of the data was examined using skewness and kurtosis. Skewness statistics ranged from -0.66 to 1.03 for non-SSPG and from -0.83 to 1.33 for SSPG. Kurtosis statistics ranged from -0.69 to 0.33 for non-SSPG and from -0.71 to 0.72 for SSPG. This indicated that the data were univariate normal (Kline, 1998). After the descriptive statistics were computed, internal reliability was examined using Cronbach's alpha. The Cronbach's alpha values were $.96, .96$, and .95 for intrinsic motivation and $.84, .77$ and .89 for extrinsic motivation in combined, non-SSPG, and SSPG groups, respectively. Thus, internal consistency of the subscales was established on the .70 cut-off standard (Nunnally \& Bernstein, 1994).

The overall and internal structures of the models were tested for each group (see Table 1). In terms of the goodness-of-fit of the structural model, the three models yielded satisfactory fit to the data, based on $\mathrm{Hu}$ and Bentler (1999): $\chi^{2}(d f)=26.08(12)$, RMSEA $=.03, \mathrm{NFI}=.99, \mathrm{CFI}=1.00$, and $\mathrm{GFI}=.99$ with the combined data set; $\chi^{2}(d f)=49.24(12)$, $\mathrm{RMSEA}=.07, \mathrm{NFI}=.98, \mathrm{CFI}=.98$, and $\mathrm{GFI}=.98$ with non-SSPG; $\chi^{2}(d f)=34.79(12)$, $\mathrm{RMSEA}=.06, \mathrm{NFI}=.99, \mathrm{CFI}=.99$, and GFI $=.98$ with SSPG. Average variance extracted (AVE) scores were calculated to test reliability of the measures. All constructs' AVE values $(.55 \sim .90)$ in the structural models were higher than .50 , indicating that more than a half of 
1 the variance for all measures were explained by their respective constructs (Fornell \&

2 Larcker, 1981). For convergent validity, all factor loadings in both models were higher

3 than .707 supporting that these measures' common variance was greater than their unique

4 variance, except one item (EM3) in non-SSPG whose factor loading was .60. In terms of

5 discriminant validity, the squared correlation coefficients between intrinsic and extrinsic

6 motivation in all models were far less than their respective AVE values, providing evidence of

7 discrimination. It was concluded that all measures in the three data sets were reliable and

8 valid.

\section{\#\#\#Insert Table 1 around here\#\#\#}

\section{Hypotheses Tasting}

First, the hypotheses 1 and 2 were tested with a structural model using the combined data set. The results showed the relationship between intrinsic motivation and participation intention was significant $(\beta=.37)$ while the relationship between extrinsic motivation and participation intention was not significant $(\beta=.04)$, with $14 \%$ of the variance explained by the model (see Table 2). Therefore, the second hypothesis was not supported.

In order to test the moderation effect of governmental financial support in the relationship between intrinsic/extrinsic motivation and participation intention, the structural model was tested with the two groups separately. Table 2 presents standardised regression coefficients for the proposed relationships. In non-SSPG, the impacts of both intrinsic motivation $(\beta=.22)$ and extrinsic motivation $(\beta=.20)$ on participation intention were significant at the .05 probability level, and the proportion of variance in participation intention explained by the relationships was $8 \%$. In SSPG, however, only intrinsic motivation $(\beta=.58)$ was a significant indicator of participation intention, and its total variance explained by the model was $34 \%$. 
Next, a multiple group analysis using a chi-square difference test was conducted to

2 test invariance of the path coefficients across the two groups simultaneously. The purpose of

3 this step was to see if the coefficient $(\beta=.58)$ in SSPG was statistically stronger than that $(\beta$

$4=.22$ ) in non-SSPG. As the alternative model (i.e., unconstrained model) included the path

5 which was set free across the two groups, it had one less degree of freedom than the null

6 model (i.e., constrained model). Table 3 shows that the test rejected the null of equality of the

7 path coefficients (.22 in non-SSPG vs. .58 in SSPG) as the chi-square difference (44.36) was

8 much greater than 3.84, yielding significance $(p<.05)$. In addition, the change of the CFI

9 values between two models was .01, and it indicates that the path coefficients in the two

10 groups should be considered different (Byrne, 2006). It is concluded that the governmental

11 financial intervention moderated the relationships between both intrinsic and extrinsic motivations and participation intention. In the schools with financial support, only students' intrinsic motivation was a significant indicator in predicting their sport participation intention. However, in the schools without financial support both intrinsic and extrinsic motivation played significant roles in predicting their participation intention while the strength of the path from intrinsic motivation to participation intention was significantly weaker than that path in the schools with financial support.

\section{Discussion}

The current study examined if governmental financial support for extracurricular physical activity could effectively enhance students' intrinsic motivation towards sport club programmes and influence their future intention to participate in the programmes. Building on the perspective of self-determination theory (Deci \& Ryan, 1985, 2012), the four hypotheses were formulated. As indicated through the data analyses, all research hypotheses were supported except the second hypothesis. The second hypothesis was developed based on 
1 organismic integration theory, which was the sub-theory of self-determination theory (Deci \&

2 Ryan, 1985). The influence of extrinsic motivation on participation intention was statistically

3 insignificant with beta coefficient of .04 among all the participants in the study including

4 SSPG and non-SSPG. Interestingly, the influence of extrinsic motivation on future intention

5 to participate was different in SSPG $(\beta=-.02, p>.05)$ and non-SSPG $(\beta=.20, p<.05)$. It

6 was found that external incentives worked as a significant factor that influenced students'

7 intention to participate in sport clubs among non-SSPG whereas it did not have such effect

8 among SSPG students. Even though small amount of variance (i.e., 4\%) in future intention to

9 participate in non-SSPG was explained by extrinsic motivation, the pattern showed that the

10 two groups differed statistically. In fact, the difference in the influence of extrinsic motivation

11 between two groups might be more important than the results of intrinsic motivation. The results of SSPG group indicated that the students participated in sport clubs without external rewards or incentives. Although sport club participation is totally voluntary, teachers usually tend to write positive statements in students' report card when students participate in sport clubs. The report cards of students are utilised as part of the application package when they advance to higher levels of education. It is deemed that students in non-SSPG enroll or participate in sport clubs expecting such incentives in return for their admission to higher education to a certain extent whereas such incentives did not work as determinant of participating in sport clubs among SSPG students.

Not having extrinsic rewards or contingencies on participation in sport clubs in SSPG projects a rich future of extracurricular physical activities in the Republic of Korea. Sport clubs in SSPG are capable of providing more repertoires and freedom of choice for the students to select their preferred sport clubs that enrich intrinsic rewards (Iwasaki \& Mannell, 1999). Alexandris et al. (2002, p. 248) highlighted that “...issues related to effective 
1 intrinsic motivation", which is enabled by the government policy development and financial

2 support. As indicated in the introduction section of the study, the health status of Korean

3 adolescents is quite serious with a high obese rate. To enhance physical fitness and lower

4 obesity among adolescents, long term participation in sport activities is necessary. In the

5 previous study, intrinsic motivation has been known to have a positive influence on physical

6 activity participation within and beyond school settings among middle school students

7 (Zhang, Solomon, Kosma, Carson, \& Gu, 2011). In addition, a plethora of evidence in

8 motivation literature that empirically examined the relationship between self-determined

9 motivation and burnout support the notion that intrinsic motivation is negatively related to

10 athletes' burnout (see Lonsdale \& Hodge, 2011, Lemyre, Roberts, \& Stray-Gundersen, 2007).

11 Thus, the results from SSPG seem quite promising in that students in SSPG are participating in sport clubs based on their intrinsic motivation, and it will lead them to prolonged participation in sport clubs until their intrinsic motivation fades away.

\section{Policy Related Ramifications}

The effectiveness of SSPG programme was turned out to be positive, and this was aligned with previous arguments of Brownson et al. (2008) and Siedentop (2009). The students in SSPG schools reported that their intrinsic motivation was the sole determinant of their intention to participate in school sport clubs. The SSPG schools spent the budget of $\$ 40,000$ per year on their school sport club programmes for two years. As the results, the students were able to enjoy quality sport club programmes, and this consequently formed a higher link from intrinsic motivation and intention to participate in school sport clubs. The new policy has also created more conducive school environment for promoting sports, exercise, and physical activities. However, as noted earlier, the financial support would not last forever. It is still possible that the SSPG schools' sport club programme will be deteriorated to the level of non-SSPG school as soon as the government stops its financial 
support. Thus, the policy makers are required to come up with a new policy enabling to maintain or advance the programmes of school sport club even without extra financial support. The current study recommends two possible strategies based on the results. The strategies will promote a sporting life style among pupils who could continue to embrace sports as a way of life even after they leave the school.

First, the management of schools needs to transform their school sport clubs from free-of-charge service to fee based service. Obviously, the process of the transformation needs to be very gradual. At the beginning, a minimal level of fee can be charged to student participants. This exercise may decrease a participation rate. However, as noted in the results, a significant part of the future intention was predicted by intrinsic motivation as long as there are many available programme choices. As school sport club programmes use this money to develop right sport programmes that match students' internal needs that motivate their actions, the intrinsically motivated students may continue participating in the club activities.

The implementations of sport programmes could form recreational groups, inter-club competitions, age-group competitions, or intermural games. In addition to minimal participation fees, the school management probably needs to utilise the results of Zhang et al. (2011). They suggested that students' physical activity participation was positively correlated with need support from PE teachers, students' need satisfaction, and intrinsic motivation (Zhang et al., 2011). In their model, intrinsic motivation was formed through PE teachers' need support (autonomy support, competence support, and relatedness support) and students' need satisfaction. The school management may be able to improve autonomy support by letting students form their own sport clubs. Students could recognise their needs, decide what benefits they want to receive through sport participation, and decide types of sport programmes and practice schedules in their own ways. This will be able to improve autonomy satisfaction among student participants. For example, the school would encourage 
and support students to create new forms of recreation as sport which are attractable to young people such as 3-on-3 basketball, ultimate frisbee, or bossaball. The second need satisfaction (i.e., competence support) can be achieved by hiring quality instructors using the fee received from student participants. However, even when quality instructors are hired from outside the school, PE teachers are strongly recommended to be present when students and instructors interact together. This is because PE teachers have better knowledge about the students and their relationships with other participants. PE teachers' behaviour and practices play a critical role in increasing student engagement (How, Whipp, Dimmock, \& Jackson, 2013). In addition, PE teachers can improve the social milieu in which the students feel connected and supported by important people (Zhang et al., 2011). This will lead to the third need satisfaction of relatedness. Obviously, this suggestion will require more efforts from the school management and PE teachers. However, this probably the only way to maintain and improve the sport club programmes that had been improved through governmental financial support.

The second recommendation is to fully utilise the human resource of sport club instructors. The Korean government has hired a total of 4,427 instructors and assigned them to 3,163 middle schools to support PE teachers since 2012. The instructors have been hired due to the policy scheme on PE curriculum hours. The middle schools accommodated 2-3 hours a week for PE lessons until 2011. However, the policy initiated in 2012 has increased the PE lessons to four hours a week. To cover up the increased PE hours, the instructors are hired based on 10-months contract. When the school management hires sport club instructors, they should understand what kinds of needs are expected from students. If students want to have a badminton sport club, the management of the school can hire the one with such qualifications. The school should be capable of pulling students towards active sport participation that could result in desirable outcomes through their quality sport programmes. 
1 This strategy can easily be implemented by setting up cooperation and communication with

2 regional sport for all associations. Currently, regional sport for all associations in Korea are

3 equipped with certified instructors in diverse sporting backgrounds. For instance, school

4 management can establish a partnership with such associations so that schools would be able

5 to accommodate quality instructors without getting into unnecessary hassle of recruitment.

6 Given the limited resources, schools need to leverage on other sport service providers in the

7 region to enhance their manpower, sport programme and facilities.

$8 \quad$ Limitation of the Study and Recommendations for Future Research

Although this study examined the SSPG and non-SSPG settings and found out how intrinsic and extrinsic motivation influenced students' future intention to participate in sport activities in different manner, further research is necessary for the betterment of school sport clubs in the Republic of Korea. The current study has a limitation in that it only included the 29 schools that were selected as SSPG in 2011. Thus, the results of the study cannot be generalised to another group of 21 schools that were added in 2012. A future study needs to incorporate the data from all the SSGP schools and see if the results of the study can be validated.

The hypotheses were tested using a cross sectional study design. This approach may have difficulty to infer the temporal associations among the constructs tested, thus a caution is needed when interpreting the causal relationships. Particularly, funded or non-funded schools may have established different dispositions (tradition, culture, coaching, facility, programme, etc.) of sport environment even before the government funding occurred. Thus, this one-shot survey may not show whether this was the case. For future research, a longitudinal or experimental study could be considered.

There is another limitation that came from the locus of the study. Although this study examined participants' intrinsic and extrinsic motivation as an antecedent of future intention 
1 of participation, other contextual factors such as available sport facilities in schools, available

2 sport club instructors (i.e., number of instructors available and their qualifications), and

3 number of sport clubs provided were not considered. Thus, a future study needs to

4 incorporate these variables to see how they can influence students' future intention to

5 participate in sport club activities and compare the strength of associations between financial

6 support and contextual factors.

Another line of a future study can be designed to see if need support and need satisfaction of Zhang et al. (2011) can be replicated in the context of the Republic of Korea

9 and sport club context. Although we utilised the results of Zhang et al. (2011) as managerial

10 ramification in improving intrinsic motivation apart from financial support from government,

11 the results of Zhang et al. (2011) are worthwhile to be replicated in the Korean context

12 because the school sport culture in the United States is quite different from the one in the

13 Republic of Korea. In addition, the data in Zhang et al. (2011) were collected from PE classes

14 which are expected to be different from sport clubs in terms of need support of PE teachers.

15 Due to the aforementioned justifications, Zhang et al.'s (2011) study could be replicated in

16 Korea using sport club data so that need support and need satisfaction can be implemented as

17 a useful tool to improve students' intrinsic motivation when financial support is not available. 


\section{References}

2 Alexandris, K., Tsorbatzoudis, C., \& Grouios, G. (2002). Perceived constraints on recreational sport participation: investigating their relationship with intrinsic motivation, extrinsic motivation and amotivation. Journal of Leisure Research, 34(3), 233-252.

Allender, S., Cowburn, G., \& Foster, C. (2006). Understanding participation in sport and physical activity among children and adults: A review of qualitative studies. Health Education Research, 21(6), 826-835.

Brownson, R. C., Kelly, C. M., Eyler, A. A., Carnoske, C., Grost, L., Handy, S. L., \& Schmid, T. L. (2008). Environmental and policy approaches for promoting physical activity in the United States: A research agenda. Journal of Physical Activity and Health, 5(4), 488-503.

Bradley, J., Keane, F., \& Crawford, S. (2013). School sport and academic achievement. Journal of School Health, 83(1), 8-13.

Bryan, C. L., \& Solmon, M. A. (2012). Student motivation in physical education and engagement in physical activity. Journal of Sport Behavior, 35(3), 267-285.

Burton, K. D., Lydon, J. E., D’Alessandro, D. U., \& Koestner, R. (2006). The differential effects of intrinsic and identified motivation on wellbeing and performance: Prospective, experimental, and implicit approaches to self-determination theory. Journal of Personality and Social Psychology, 91(4), 750-762.

Byrne, B. M. (2006). Structural equation modelling with EQS: Basic concepts, applications, and programming (2nd ed.). Mahwah: NJ: Laurence Erlbaum Associates.

Deci, E. L., \& Ryan, R. M. (1985). Intrinsic motivation and self-determination in human behavior. New York: Plenum Press.

Deci, E. L., \& Ryan, R. M. (1987). The support of autonomy and control of behavior. Journal of Personality and Social Psychology, 53(6), 1024-1037. 
1 Deci, E. L., \& Ryan, R. M. (2000). The" what" and" why" of goal pursuits: Human needs and the self-determination of behavior. Psychological Inquiry, 11(4), 227-268.

Deci, E. L., \& Ryan, R. M. (2002). Handbook of self-determination theory research. Rochester, NY: University of Rochester Press.

Fornell, C., \& Larcker, D. F. (1981). Evaluating structural equation models with unobservable variables and measurement error. Journal of Marketing Research, 18(February), 39-50.

Gagné, F. (2011). Academic talent development and the equity issue in gifted education. Talent Development and Excellence, 3(1), 3-22.

Guay, F., Vallerand, R. J., \& Blanchard, C. (2000). On the assessment of situational intrinsic and extrinsic motivation: The situational motivation scale (SIMS). Motivation and Emotion, 24(3), 175-213.

Hagger, M., \& Chatzisarantis, N. (2008). Self-determination theory and the psychology of exercise. International Review of Sport and Exercise Psychology, 1(1), 79-103.

Hair, J. F., Black, B., Babin, B., \& Anderson, R. E. (2009). Multivariate data analysis (7th ed). Upper Saddle River, NJ: Prentice-Hall.

How, Y. M., Whipp, P., Dimmock, J., \& Jackson, B. (2013). The effects of choice on autonomous motivation, perceived autonomy support, and physical activity levels in high school physical education. Journal of Teaching in Physical Education, 32, 131-148.

Howe, C., \& Freedson, P. (2008). Physical activity and academic performance. PCPFS Newsletter, Fall, 1-4.

Houlihan, B. (2000). Sporting excellnece, schools and sports development: The politics of crowded policy spaces. European Physical Education Review, 6(2), 171-193.

Hu, L., \& Bentler, P. M. (1999). Cutoff criteria for fit indiexes in covariance structure analysis: Conventional criteria versus new laternatives. Structural Equation Modeling, 6(1), 1-55. Iso-Ahola, S. E. (1999). Motivational foundations of leisure. In E. Jackson \& T. Burton 
(Eds.), Leisure studies: Prospects for the twenty-first century (pp. 35-51). State College, PA: Venture.

Iwasaki, Y., \& Mannell, R. (1999). Situational and personality influences on intrinsically motivated leisure behavior: Interaction effects and cognitive processes. Leisure Sciences, 21(4), 287-306.

Kang, H. K. (2010). Effects of walking exercise on the changes of body compostiion and immunoglobulin levels of obseseelementry male students. Korean Journal of Elementary Physical Educaiton, 16(3), 157-168.

Kline, R. B. (1998). Principles and practice of structural equation modeling. New York: The Guilford Press.

Lemyre, P. N., Roberts, G. C., \& Stray-Gundersen, J. (2007). Motivation, overtraining, and burnout: Can self-determined motivation predict overtraining and burnout in elite athletes? European Journal of Sport Science, 7(2), 115-126.

Lepper, M. R., Corpus, J. H., \& Iyengar, S. S. (2005). Intrinsic and extrinsic orientations in the classroom: Age differences and academic correlates. Journal of Educational Psychology, 97(2), 184-196.

Linnenbrink, E. A., \& Pintrich, P. R. (2002). Motivation as an enabler for academic success. School Psychology Review, 31(3), 313-327.

Lonsdale, C., \& Hodge, K. (2011). Temporal ordering of motivational quality and athlete burnout in elite sport. Medicine \& Science in Sports \& Exercise, 43(5), 913-921.

Marchevsky, D. (1999). Quick rating of depressed mood. British Journal of Psychiatry, $175(3), 289-290$.

Martindale, R. J. J., Collins,D., \& Daubney, J. (2005). Talent development: A guide for practice and research within sport. Quest, 57(4), 353-375. 
1 Ministry of Education.

2 Nagy, M. S. (2002). Using a single-item approach to measure facet job satisfaction. Journal of Occupational and Organizational Psychology, 75(1), 77-86.

4 Nunnally, J. C., \& Bernstein, I. H. (1994). Psychometric theory (3rd ed). New York:

5 McGraw-Hill.

OECD (2018). The OECD Programme for International Student Assessment 2015: Results in focus. Retrieved from https://www.oecd.org/pisa/pisa-2015-results-in-focus.pdf

Oshagbemi, T. (1999). Overall job satisfaction: How good are single versus multiple-item measures? Journal of Managerial Psychology, 14(5), 388-403.

Podsakoff, P. M., MacKenzie, S. B., Lee, J. Y., \& Podsakoff, N. P. (2003). Common method biases in behavioral research: A critical review of the literature and recommended remedies. Journal of Applied Psychology, 88(5), 879-903.

Pratt, M., Perez, L. G., Goenka, S., Brownson, R. C., Bauman, A., Sarmiento, O. L., \& Hallal, P. C. (2015). Can population levels of physical activity be increased? Global evidence and experience. Progress in Cardiovascular Diseases, 57(4), 356-367.

Roberts, G. C., \& Treasure, D. C. (2012). Advances in motivation in sport and exercise (3rd ed). Champaign, IL: Human Kinetics.

Robins, R. W., Hendin, H. M., \& Trzesniewski, K. H. (2001). Measuring global self-esteem: Construct validation of a single-item measure and the Rosenberg Self-Esteem Scale. Personality and Social Psychology Bulletin, 27(2), 151-161.

Ryan, R. M., Williams, G. C., Patrick, H., \& Deci, E. L. (2009). Self-determination theory and physical activity: The dynamics of motivation in development and wellness. Hellenic Journal of Psychology, 6(2), 107-124.

Ryan, R. M., \& Deci, E. L. (2007). Active human nature: Self-determination theory and the promotion and maintenance of sport, exercise, and health. In M. S. Hagger \& N. L. D. 
Chatzisarantis (Eds.), Intrinsic motivation and self-determination in exercise and sport (pp. 1-19). Champaign, IL: Human Kinetics.

Siedentop, D. L. (2009). National plan for physical activity: Education sector. Journal of Physical Activity and Health, 6(2), 168-180.

Spitath, B., \& Spitath, F. M. (2005). Longitudinal analysis of the link between learning motivation and competence beliefs among elementary school children. Learning and Instruction, 15(2), 87-102.

Statistics Korea (2018). 2018 adolescent statistics. Retrieved from http://kostat.go.kr

Story, M., Nanney, M. S., \& Schwartz, M. B. (2009). Schools and obesity prevention: Creating school environments and policies to promote healthy eating and physical activity. The Milbank Quarterly, 87(1), 71-100.

Teixeira, P. J., Carraça, E. V., Markland, D., Silva, M. N., \& Ryan, R. M. (2012). Exercise, physical activity, and self-determination theory: A systematic review. International Journal of Behavioural Nutrition and Physical Activity, 9(1), 78.

Tsorbatzoudis, H., Alexandris, K., Zahariadis, \& Grouios, G. (2006). Examining the relationship between recreational sport participation and intrinsic and extrinsic motivation and amotivation. Perceptual and Motor Skills, 103(2), 363-374.

Vazou, S., Gavrilou, P., Mamalaki, E., Papanastasiou, A., \& Sioumala, N. (2012). Does integrating physical activity in the elementary school classroom influence academic motivation? International Journal of Sport and Exercise Psychology, 10(4), 251-263.

Vuori, I., Lankenau, B., \& Pratt, M. (2004). Physical activity policy and program development: The experience in Finland. Public Health Reports, 119(3), 331-345.

Wanous, J. P., \& Hudy, M. J. (2001). Single-item reliability: A replication and extension. Organizational Research Methods, 4(4), 361-375.

Zhang, T., Solomon, M. A., Kosma, M., Carson, R. L., \& Gu, X. (2011). Need support, need 

satisfaction, intrinsic motivation, and physical activity participation among middle school students. Journal of Teaching in Physical Education. 30(1), 51-68. 
Table 1

Overall and Internal Structure of Observed Variables in the Structural Models

\begin{tabular}{|c|c|c|c|c|c|c|c|c|c|c|}
\hline \multirow{2}{*}{$\begin{array}{l}\text { Latent } \\
\text { variable }\end{array}$} & \multirow{2}{*}{$\begin{array}{l}\text { Observed } \\
\text { variable }\end{array}$} & \multicolumn{3}{|c|}{$\operatorname{All}(N=1144)$} & \multicolumn{3}{|c|}{ Non-SSPG Group $(n=573)$} & \multicolumn{3}{|c|}{ SSPG Group $(n=571)$} \\
\hline & & $\beta$ & $\alpha$ & AVE & $\beta$ & $\alpha$ & AVE & $\beta$ & $\alpha$ & AVE \\
\hline \multirow{3}{*}{$\begin{array}{l}\text { Intrinsic } \\
\text { motivation }\end{array}$} & IM1 & $.95^{*}$ & \multirow{3}{*}{.96} & \multirow{3}{*}{.88} & $.94 *$ & \multirow{3}{*}{.96} & \multirow{3}{*}{.90} & $.95^{*}$ & \multirow{3}{*}{.95} & \multirow{3}{*}{.87} \\
\hline & IM2 & $.96^{*}$ & & & $.98 *$ & & & $.95^{*}$ & & \\
\hline & IM3 & $.90 *$ & & & $.93^{*}$ & & & $.89 *$ & & \\
\hline \multirow{3}{*}{$\begin{array}{l}\text { Extrinsic } \\
\text { motivation }\end{array}$} & EM1 & $.74 *$ & \multirow{3}{*}{.84} & \multirow{3}{*}{.64} & $.72 *$ & & \multirow{3}{*}{.55} & $.76^{*}$ & \multirow{3}{*}{.89} & \multirow{3}{*}{.75} \\
\hline & EM2 & $.87 *$ & & & $.87 *$ & .77 & & $.89^{*}$ & & \\
\hline & EM3 & $.79 *$ & & & \multicolumn{2}{|l|}{$.60^{*}$} & & $.94 *$ & & \\
\hline \multirow{5}{*}{\multicolumn{2}{|c|}{ Goodness-of-fit }} & \multirow{2}{*}{\multicolumn{3}{|c|}{$\begin{array}{l}\chi^{2}(d f)=26.08(12) \\
\text { RMSEA }=.03\end{array}$}} & & 49.2 & & & 34.79 & \\
\hline & & & & & \multicolumn{3}{|c|}{ RMSEA $=.07$} & \multicolumn{3}{|c|}{ RMSEA $=.06$} \\
\hline & & \multicolumn{3}{|c|}{$\mathrm{NFI}=.99$} & \multicolumn{3}{|c|}{$\mathrm{NFI}=.98$} & \multicolumn{3}{|c|}{$\mathrm{NFI}=.99$} \\
\hline & & \multicolumn{3}{|c|}{$\mathrm{CFI}=1.00$} & \multirow{2}{*}{\multicolumn{3}{|c|}{$\begin{array}{l}\mathrm{CFI}=.98 \\
\mathrm{GFI}=98\end{array}$}} & \multicolumn{3}{|c|}{$\mathrm{CFI}=.99$} \\
\hline & & \multicolumn{3}{|c|}{$\mathrm{GFI}=.99$} & & & & $\mathrm{GH}$ & & \\
\hline
\end{tabular}

$*$ Factor loadings were significant at $\alpha=.05$. 
Table 2

Path Coefficient in the Structural Models

\begin{tabular}{|c|c|c|c|c|c|c|c|}
\hline \multirow{2}{*}{$\begin{array}{l}\text { Endogenous } \\
\text { variable }\end{array}$} & \multirow{2}{*}{ Exogenous variable } & \multicolumn{2}{|c|}{ All $(N=1144)$} & \multicolumn{2}{|c|}{ Non-SSPG Group $(n=573)$} & \multicolumn{2}{|c|}{ SSPG Group $(n=571)$} \\
\hline & & $\beta$ & $t$ & $\beta$ & $t$ & $\beta$ & $t$ \\
\hline \multirow{3}{*}{$\begin{array}{l}\text { Participation } \\
\text { intention }\end{array}$} & Intrinsic motivation & $.37 *$ & 12.75 & $.22 *$ & 5.25 & $.58 *$ & 15.08 \\
\hline & Extrinsic motivation & .04 & 1.37 & $.20^{*}$ & 4.54 & -.02 & -0.60 \\
\hline & Total variance explained & \multicolumn{2}{|c|}{$R^{2}=.14$} & \multicolumn{2}{|c|}{$R^{2}=.08$} & \multicolumn{2}{|c|}{$R^{2}=.34$} \\
\hline
\end{tabular}

$*$ Path coefficients were significant at $\alpha=.05$. 
Table 3

Test of Invariance of the Path Coefficients across the Two Groups

\begin{tabular}{lccl}
\hline Model & $\chi^{2}(d f)$ & CFI & Test of invariance \\
\hline $\begin{array}{l}\mathrm{H}_{\mathrm{O}} \text { : All parameters constrained to } \\
\text { be equal }\end{array}$ & $364.45(40)$ & .93 & \\
$\begin{array}{l}\mathrm{H}_{\mathrm{A}} \text { : Unconstrained path coefficient } \\
\text { from intrinsic motivation to }\end{array}$ & $320.09(39)$ & .94 & $\begin{array}{l}\mathrm{H}_{\mathrm{O}}-\mathrm{H}_{\mathrm{A}}: \\
\text { participation intention }\end{array}$ \\
\hline
\end{tabular}

